PROSIDING XXVII DAN KONGRES X PERHAPI 2018

\title{
PENENTUAN VOLUME POTENSI LONGSORAN LERENG TAMBANG TERBUKA MENGGUNAKAN METODE KESETIMBANGAN BATAS 3 DIMENSI
}

(Determining Volume of Potential Failure of an Open Pit Slope Using 3D Limit Equilibrium Method)

\author{
By : \\ 1)* Masagus Ahmad Azizi ${ }^{1)}$ Irfan Marwanza ${ }^{1)}$ Nadya A. Hartanti \\ ${ }^{1)}$ Program Studi Teknik Pertambangan FTKE Universitas Trisakti \\ Jalan Kyai Tapa No.1, Grogol, Jakarta Barat 11440, Indonesia. \\ Email : masagus.azizi@trisakti.ac.id \\ Phone : 08112315789
}

\begin{abstract}
Abstrak
Salah satu dampak dari suatu risiko longsoran lereng tambang terbuka adalah jatuhnya material longsor ke dalam tambang yang sedang melakukan operasi tambang yang berakibat dapat menimbulkan terjadinya fatalitas dan/atau cidera bagi pekerja, serta kerusakan properti perusahaan. Oleh sebab itu analisis kestabilan suatu lereng selain digunakan untuk menentukan nilai faktor keamanan (FK) dan probabilitas kelongsoran (PK) lereng, juga dapat memprediksi besaran volume longsoran bila terjadi kegagalan dalam disain lereng. Penelitian ini menggunakan metode kesetimbangan batas (limit equilibrium method) 3 dimensi dalam penentuan volume longsoran lereng dengan lokasi pada tambang terbuka batugamping di Rembang, Jawa Tengah. Ke depan diharapkan pendekatan ini dapat dimanfaatkan para praktisi untuk perencanaan mitigasi kelongsoran lereng.

Kata Kunci : Tambang terbuka, stabilitas lereng, metode kesetimbangan batas 3 dimensi, dampak longsoran
\end{abstract}

\begin{abstract}
One of the consequences from a risk of open pit failure is the fallen of the failure material in a mine that is doing the mine operation that can cause fatality and/or injury to workers, and damage to company properties. Therefore, the slope stability analysis is not only used to determine the safety factor (SF) and failure probability (FP), but it can also predict the amount of the volume of failure if there is any fault in the slope design. This research used 3D limit equilibrium method in determining the volume of potential failure of an open pit limestone mine in Rembang, Central Java. In the future, it is hoped that this approach can be utilized by practitioners for mitigation of slope failure planning.

Keywords : Open pit, slope stability, 3D limit equilibrium method, consequence of failure

\section{PENDAHULUAN}

Resiko longsoran dapat dikuantifikasi dengan mengalikan probabilitas kelongsoran dan konsekuensi. Manajemen resiko perlu dilakukan untuk meyakinkan potensi
\end{abstract}


resiko suatu operasi penambangan dapat terkontrol dan terukur. Penelitianpenelitian yang berkaitan dengan hal ini dalam M.A. Azizi dkk (2011, 2013, 2014); R.K. Wattimena dkk (2012, 2013); S. Kramadibrata dkk (2012, 2013); H.A. Ardhi dkk (2017), dan R.A. Abdullah dkk (2018). Volume longsoran merupakan salah satu konsekuensi yang ada di lingkup tambang terbuka. Dengan demikian akan lebih baik jika volume suatu potensi longsoran dapat diestimasi agar dapat diketahui seberapa besar resiko dari potensi longsoran tersebut.

Analisis kestabilan lereng dengan metode kesetimbangan batas membutuhkan asumsi bidang longsor dalam menghitung FK, khususnya jika pendekatannya adalah tipe longsoran busur. Dalam analisis 2 dimensi (2D) metode pencarian bidang longsor yang sering digunakan adalah Grid Search. Grid Search banyak dipakai karena prinsip kerjanya yang sederhana dan mudah dipahami.

Analisis kestabilan lereng secara 3 dimensi (3D) sekarang semakin terasa dibutuhkan tetapi masih jarang diaplikasikan. Hartanti (2018) menyatakan bahwa analisis secara 2D tidak dapat dijadikan sebagai patokan utama dalam menilai kestabilan suatu lereng. Selain itu, dengan menganalisis secara 3D volume potensi longsoran juga dapat diperkirakan. Untuk itu, dalam penelitian ini analisis dilakukan secara 3D untuk mendapatkan lokasi potensi longsoran dan estimasi volume yang representatif.

\section{METODE KESETIMBANGAN BATAS 3 DIMENSI}

Prinsip kestabilan lereng yang dipakai dalam penelitian ini adalah prinsip pengembangan yang diajukan oleh Cheng dan Yip (2007). Untuk mendapatkan nilai faktor keamanan (FK), bidang luncur didefinisikan terlebih dahulu secara 3 dimensi dan didikritisasi menjadi kolom-kolom vertikal. FK kemudian dihitung berdasarkan arah longsoran (sliding direction, $\mathrm{a}_{\mathrm{i}}$ ) tertentu pada arah $\mathrm{x}, \mathrm{y}$, dan $\mathrm{z}$. Jika ketiga nilai tersebut belum sama FK dihitung kembali dengan $a_{i}$ baru. Ketika FK telah diperoleh secara otomatis tiap kolom tersebut kemudian dihitung volumenya dan dikumulatifkan terhadap seluruh kolom pada massa gelincir tersebut untuk penentuan estimasi volume potensi longsoran. Untuk informasi yang lebih lanjut terkait detail pembagian gaya-gaya yang bekerja pada suatu kolom dan rumus perhitungan FK dapat dilihat dalam Cheng dan Yip (2007).

\section{METODOLOGI}

Penentuan FK dan volume longsoran dilakukan dengan menggunakan perangkat lunak Slide3 (lisensi resmi dari Rocscience). Metode yang dipakai yaitu metode Bishop dengan metode pencarian bidang longsor Grid Search. Prinsip Grid Search yaitu membuat pusat gelincir dalam bentuk titik yang letak dan kerapatannya diatur berdasarkan grid box sehingga dari setiap titik akan dihitung nilai FK dan titik satu dengan yang lain memiliki nilai FK yang berbeda-beda. Titik dengan FK paling rendah akan dijadikan sebagai hasil final simulasi. Analisis 3D dilakukan pada keseluruhan pit dalam kondisi kering dengan memvariasikan jumlah kolom maks dalam sumbu $\mathrm{x}$ atau y (Max Columns in $x$ or $y$ ), jumlah radii per poin (number of radii per point), dan banyak titik dalam grid box. Max Columns in $x$ or $y$ adalah jumlah kolom maksimum suatu massa longsoran pada sumbu $\mathrm{x}$ atau y. Number of radii per point yang dimaksud disini adalah jumlah bidang longsor yang dibuat dan dihitung FK-nya dalam area yang masih dapat ditolerir dan masuk akal (Rmin 
sampai Rmax) untuk membuat bidang longsor untuk setiap titik dalam grid box (lihat Gambar 2). Rmin dan Rmax ditentukan secara otomatis berdasarkan lokasi titik dan geometri lereng. Titik dalam grid box merepresentasikan pusat gelincir. Litologi (berdasarkan klasifikasi yang ada di perusahaan tersebut) dalam penelitian ini terdiri dari 2 yaitu batugamping High Grade (HG) dan Low Grade (LG). Model geologi dibuat berdasarkan lokasi dan posisi tiap litologi setiap lubang bor.

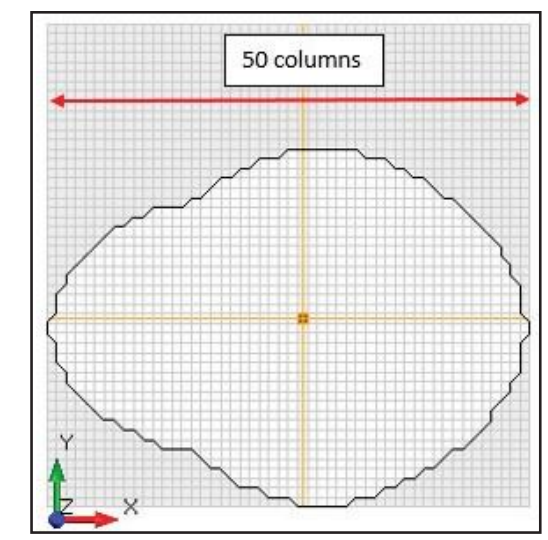

Gambar 1. Deskripsi Max Columns in x or y 50 (www.rocscience.com)

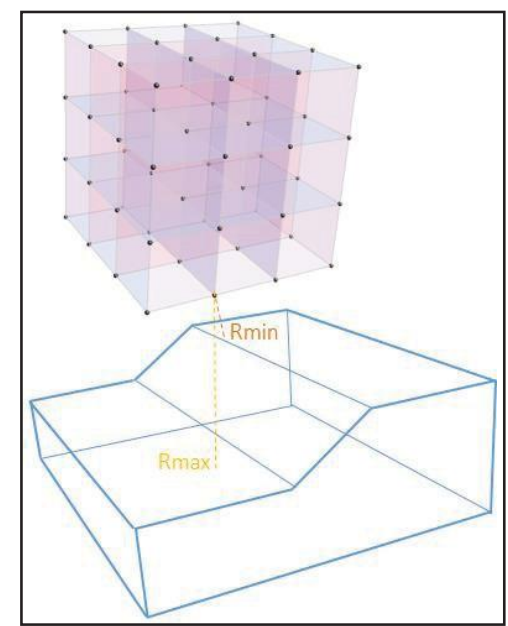

Gambar 2. Batasan Area Dalam Pembuatan Bidang Longsor

(www.rocscience.com)

\section{DATA}

Data lubang bor serta data sifat fisik dan mekanik material yang digunakan dalam penelitian ini diadopsi dari Prakoso (2018) dan Amala (2018). Lokasi lubang bor dan kedalaman litologi tiap lubang bor dapat dilihat dalam Tabel 1 yang terdiri dari ID bor, koordinat bor, dan kedalaman tiap litologi. Tabel 2 merupakan parameter masukan material properties tiap litologi yang terdiri dari data berat jenis, kohesi, sudut gesek dalam (phi), dan kuat tarik material. Karena dalam analisis ini menggunakan Grid Search untuk mencari bidang longsor dengan FK minimum maka grid box perlu didefinisikan dengan ukuran tertentu. Detail mengenai posisi 
grid box, ukuran grid box, banyak titik yang digunakan pada tiap sumbu, dan jarak antartitik pada tiap sumbu tersedia pada Tabel 3.

Tabel 1. Lokasi Kedalaman Litologi Pada Lubang Bor (Prakoso, 2018; Amala, 2018)

\begin{tabular}{ccccccc}
\hline \multirow{2}{*}{$\begin{array}{c}\text { Titik } \\
\text { Bor }\end{array}$} & \multirow{2}{*}{ Absis } & \multirow{2}{*}{ Ordinat } & Elevasi & \multicolumn{3}{c}{ Kedalaman (m) } \\
\cline { 5 - 7 } & & & & LG (atas) & HG & LG (bawah) \\
\hline DH04 & 557997 & 9238904 & 291 & $0-18.3$ & $18.3-38.2$ & $38.2-48$ \\
\hline DH06 & 557932 & 9238833 & 300 & $0-8.8$ & $8.8-48.9$ & $48.9-87.9$ \\
\hline DH07 & 558015 & 9238805 & 297 & $0-27.6$ & $27.6-42.9$ & $42.9-53.4$ \\
\hline DH08 & 558087.5 & 9238804.9 & 289.7 & $0-0.28$ & $0.28-60.9$ & $60.9-68.4$ \\
\hline DH09 & 557895.5 & 9238604.9 & 243.3 & $0-1$ & $1-14.35$ & $14.35-34$ \\
\hline
\end{tabular}

Tabel 2. Karakteristik Batuan (Prakoso, 2018; Amala, 2018)

\begin{tabular}{ccccc}
\hline Litologi & Berat jenis $(\mathrm{kN} / \mathrm{m} 3)$ & Kohesi $(\mathrm{kPa})$ & Phi $\left(^{\circ}\right)$ & Kuat Tarik $(\mathrm{kPa})$ \\
\hline HG & 20.43 & 250 & 40.7 & 2550 \\
\hline LG & 19.79 & 230 & 40.1 & 2250 \\
\hline
\end{tabular}

Tabel 3. Ukuran Grid Box dan Banyak Titik Yang Dipakai

\begin{tabular}{|c|c|c|c|c|c|c|c|}
\hline \multirow{2}{*}{ Koordinat } & \multirow{2}{*}{$\mathrm{x}$} & \multirow{2}{*}{$\mathrm{y}$} & \multirow{2}{*}{$\mathrm{Z}$} & \multirow{2}{*}{ Banyak Titik } & \multicolumn{3}{|c|}{ Jarak antar titik (m) di sumbu- } \\
\hline & & & & & $\mathrm{x}$ & $\mathrm{y}$ & $\mathrm{z}$ \\
\hline min corner & 557760 & 9238480 & 290 & $10 \times 10 \times 5$ & 48.89 & 48.89 & 50 \\
\hline max corner & 558200 & 9238920 & 490 & $20 \times 20 \times 10$ & 23.16 & 23.16 & 22.22 \\
\hline delta & 440 & 440 & 200 & $30 \times 30 \times 15$ & 15.17 & 15.17 & 14.29 \\
\hline
\end{tabular}

\section{HASIL \& DISKUSI}

Hasil analisis menunjukkan lokasi dengan FK paling rendah di timur laut dan utara pit. Hal ini disebabkan adanya perbedaan kerapatan titik. Dalam analisis 3D, secara logis jika ternyata lokasi global minimum berada di lokasi A dan pada lokasi tersebut titik-titik disana tidak banyak atau bahkan sedikit maka sistem dapat saja menyimpulkan lokasi global minimum di lokasi lain. Dengan demikian kerapatan titik menjadi hal yang sensitif untuk analisis kestabilan lereng 3D, terutama jika area tersebut memiliki variasi geologi yang kecil.

Berdasarkan lokasi global minimum tiap simulasi secara 3D, dapat diketahui bahwa lokasi global minimum sebenarnya berada di utara pit karena nilai FK yang lebih rendah, dengan rata-rata estimasi volume potensi longsoran sebesar 190.000 $\mathrm{m}^{3}$. Volume potensi longsoran tiap simulasi berbeda-beda dikarenakan penentuan volume bergantung pada lokasi titik dalam grid box, jumlah kolom maks di sumbu $\mathrm{x}$ atau $\mathrm{y}$, jumlah radii per poin, dan banyak titik yang dibuat dalam grid box. Dengan demikian dalam memperkirakan besar volume potensi suatu longsoran sangat perlu dilakukan simulasi dengan variabel-variabel yang bervariasi sehingga dapat diketahui range besarannya.

Masalah waktu komputasi dalam analisis 3D sangat menjadi perhatian dalam penelitian ini. Hal ini dikarenakan Grid Search bergantung pada banyaknya titik yang di-assign. Jika titik yang di pakai semakin banyak maka komputasinya pun akan menjadi lebih lama. Yang akan menjadi masalah di kemudian hari adalah jika dilakukan analisis kestabilan lereng 3D dengan Grid Search pada area yang luas. Area yang luas membutuhkan grid box yang besar pula sehingga jika ingin hasilnya 
akurat (mendapatkan hasil di lokasi global minimum) maka titik yang diperlukan harus sangat rapat. Albataineh (2006) menyatakan bahwa pengotomisasian teknik pencarian dapat menjadi pekerjaan yang tidak praktis jika teknik klasik digunakan. Teknik optimasi yang canggih menunjukkan potensi yang menjanjikan untuk pengembangan lebih lanjut dan pengaplikasian di masa depan dalam masalah stabilitas lereng dan rekayasa geoteknik (Albataineh, 2006). Dengan demikian, analisis 3D kedepannya lebih dianjurkan menggunakan metode pencarian bidang longsor dengan teknik optimasi.

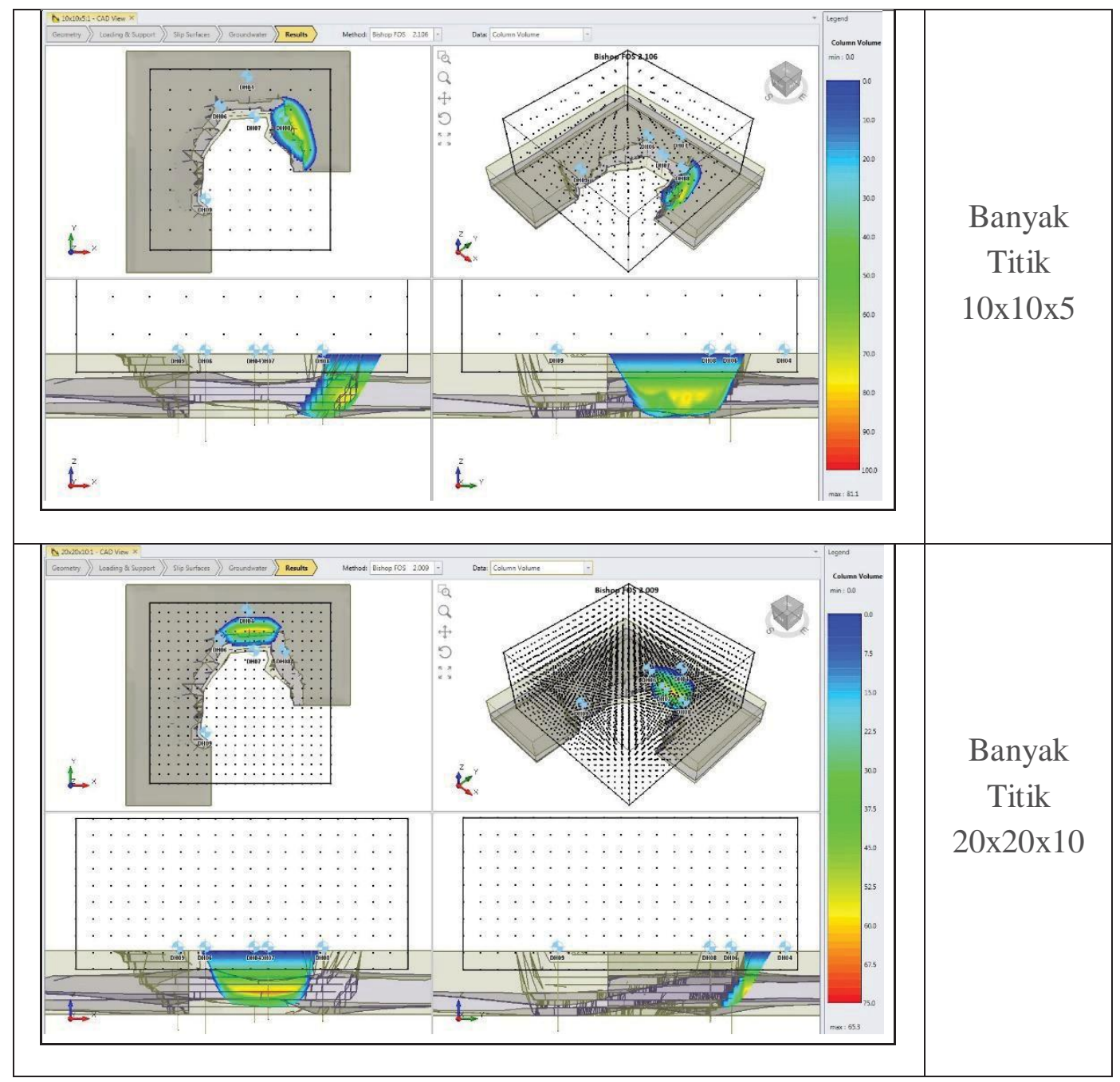




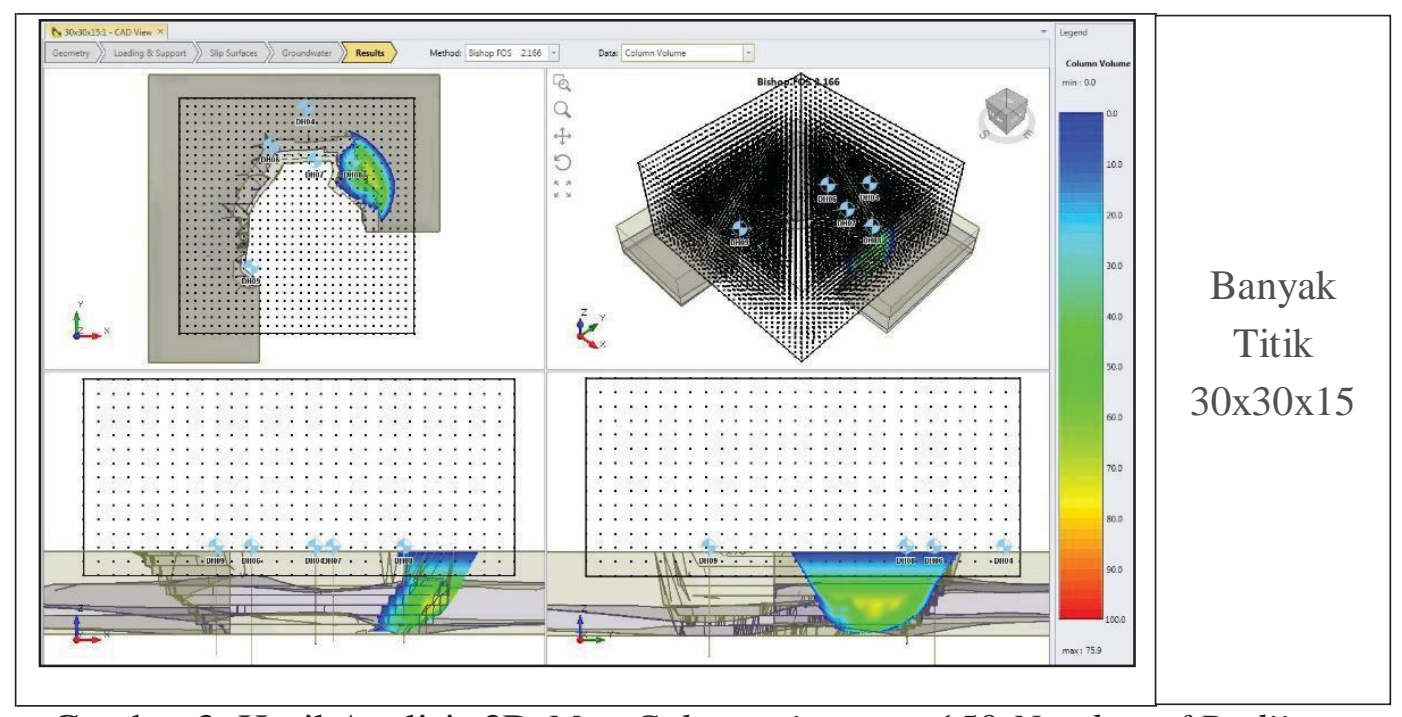

Gambar 3. Hasil Analisis 3D Max Columns in x or y 150 Number of Radii per Point 10

Tabel 4. Prediksi Volume Longsoran Berdasarkan 3D Grid Search

\begin{tabular}{|c|c|c|c|c|c|c|c|}
\hline $\begin{array}{l}\text { Jumlah Kolom } \\
\text { Maks dalam } \\
\text { X or Y }\end{array}$ & $\begin{array}{c}\text { Jumlah radii } \\
\text { per poin }\end{array}$ & $\begin{array}{c}\text { Banyak } \\
\text { titik }\end{array}$ & rK & LoKası & $\begin{array}{l}\text { Volume } \\
\left(\mathrm{m}^{3}\right)\end{array}$ & $\begin{array}{l}\text { Berat } \\
(\mathrm{kN})\end{array}$ & $\begin{array}{l}\text { Waktu } \\
\text { (menit) }\end{array}$ \\
\hline & \multirow{3}{*}{10} & 10x10x5 & 2.15 & $\mathrm{TL}$ & 179813 & 3624370 & 1.11 \\
\hline & & $20 \times 20 \times 10$ & 2.11 & $\mathrm{TL}$ & 282903 & 5701680 & 2.79 \\
\hline & & $30 \times 30 \times 15$ & 2.06 & $\mathrm{U}$ & 162000 & 3239480 & 5.77 \\
\hline & \multirow{3}{*}{20} & $10 \times 10 \times 5$ & 2.15 & $\mathrm{TL}$ & 179813 & 3624370 & 1.25 \\
\hline & & $20 \times 20 \times 10$ & 2.04 & $\mathrm{U}$ & 166189 & 3324020 & 3.78 \\
\hline & & $30 \times 30 \times 15$ & 2.03 & $\mathrm{U}$ & 165195 & 3304790 & 13.74 \\
\hline \multirow{13}{*}{50} & \multirow{3}{*}{30} & $10 \times 10 \times 5$ & 2.15 & $\mathrm{TL}$ & 179813 & 3624370 & 1.42 \\
\hline & & $20 \times 20 \times 10$ & 2.04 & $\mathrm{U}$ & 170481 & 3409280 & 7.28 \\
\hline & & $30 \times 30 \times 15$ & 2.00 & $\mathrm{U}$ & 192759 & 3857490 & 24.97 \\
\hline & \multirow{3}{*}{40} & $10 \times 10 \times 5$ & 2.14 & $\mathrm{TL}$ & 258577 & 5209830 & 1.83 \\
\hline & & $20 \times 20 \times 10$ & 2.04 & $\mathrm{U}$ & 166189 & 3324020 & 8.14 \\
\hline & & $30 \times 30 \times 15$ & 2.13 & $\mathrm{TL}$ & 230271 & 4639730 & 56.08 \\
\hline & \multirow{3}{*}{50} & $10 \times 10 \times 5$ & 2.15 & $\mathrm{TL}$ & 179813 & 3624370 & 1.96 \\
\hline & & $20 \times 20 \times 10$ & 2.01 & $\mathrm{U}$ & 193695 & 3877380 & 13.78 \\
\hline & & $30 \times 30 \times 15$ & 2.09 & $\mathrm{TL}$ & 231300 & 4656100 & 74.42 \\
\hline & & $10 \times 10 \times 5$ & 2.15 & $\mathrm{TL}$ & 179482 & 3618350 & 2.06 \\
\hline & 10 & $20 \times 20 \times 10$ & 2.09 & $\mathrm{U}$ & 148023 & 2960280 & 3.59 \\
\hline & $30 \times 30 \times 15$ & $2.14 \quad \mathrm{TL}$ & 1799 & & 950 & 8.65 & \\
\hline & $10 \times 10 \times 5$ & $2.15 \quad$ TL & 1794 & & 350 & 2.25 & \\
\hline \multirow{10}{*}{60} & \multirow[t]{2}{*}{20} & $20 \times 20 \times 10$ & 2.00 & $\mathrm{U}$ & 190470 & 3811850 & 5.93 \\
\hline & & $30 \times 30 \times 15$ & 2.16 & $\mathrm{TL}$ & 169015 & 3405000 & 19.51 \\
\hline & \multirow{3}{*}{30} & $10 \times 10 \times 5$ & 2.15 & $\mathrm{TL}$ & 179482 & 3618350 & 2.48 \\
\hline & & $20 \times 20 \times 10$ & 2.01 & $\mathrm{U}$ & 194364 & 3890270 & 7.23 \\
\hline & & $30 \times 30 \times 15$ & 2.09 & $\mathrm{TL}$ & 247998 & 4995250 & 32.72 \\
\hline & \multirow{3}{*}{40} & $10 \times 10 \times 5$ & 2.16 & $\mathrm{TL}$ & 173000 & 3486620 & 2.08 \\
\hline & & $20 \times 20 x 10$ & 2.00 & $\mathrm{U}$ & 190470 & 3811850 & 10.26 \\
\hline & & $30 \times 30 \times 15$ & 2.10 & $\mathrm{TL}$ & 255137 & 5137040 & 49.23 \\
\hline & \multirow{2}{*}{50} & $10 \times 10 \times 5$ & 2.17 & $\mathrm{TL}$ & 194720 & 3922270 & 9.00 \\
\hline & & $20 \times 20 \times 10$ & 2.03 & $\mathrm{U}$ & 176015 & 3523090 & 19.75 \\
\hline
\end{tabular}




\begin{tabular}{|c|c|c|c|c|c|c|c|}
\hline \multirow[t]{8}{*}{$\begin{array}{l}\text { Jumıan Koıоm } \\
\text { Maks dalam } \\
\text { X or Y }\end{array}$} & \multirow[t]{2}{*}{$\begin{array}{l}\text { Jumlah radii } \\
\text { per poin }\end{array}$} & $\begin{array}{c}\text { Banyak } \\
\text { titik }\end{array}$ & rn & LUKasI & $\begin{array}{l}\text { Volume } \\
\left(\mathrm{m}^{3}\right)\end{array}$ & $\begin{array}{c}\text { Berat } \\
(\mathrm{kN})\end{array}$ & $\begin{array}{l}\text { Waktu } \\
\text { (menit) }\end{array}$ \\
\hline & & $30 \times 30 \times 15$ & 2.14 & TL & 263876 & 5316990 & 101.35 \\
\hline & \multirow{3}{*}{10} & 10x10x5 & 2.02 & $\mathrm{TL}$ & 133806 & 2696870 & 4.24 \\
\hline & & $20 \times 20 \times 10$ & 2.01 & $\mathrm{U}$ & 171479 & 3431770 & 4.34 \\
\hline & & $30 \times 30 \times 15$ & 2.15 & $\mathrm{TL}$ & 173864 & 3504560 & 14.39 \\
\hline & \multirow{3}{*}{20} & 10x10x5 & 2.02 & TL & 133806 & 2696870 & 4.58 \\
\hline & & $20 \times 20 \times 10$ & 2.00 & $\mathrm{U}$ & 192896 & 3860000 & 8.09 \\
\hline & & $30 \times 30 \times 15$ & 2.11 & $\mathrm{TL}$ & 260548 & 5246540 & 25.06 \\
\hline \multirow{9}{*}{70} & \multirow{3}{*}{30} & 10x10x5 & 2.02 & $\mathrm{TL}$ & 133806 & 2696870 & 4.86 \\
\hline & & $20 \times 20 \times 10$ & 2.00 & $\mathrm{U}$ & 180079 & 3603750 & 10.16 \\
\hline & & $30 \times 30 \times 15$ & 2.18 & $\mathrm{TL}$ & 189323 & 3817720 & 40.48 \\
\hline & \multirow{3}{*}{40} & 10x10x5 & 2.02 & $\mathrm{TL}$ & 133806 & 2696870 & 6.58 \\
\hline & & $20 \times 20 \times 10$ & 2.00 & $\mathrm{U}$ & 192896 & 3860000 & 25.52 \\
\hline & & $30 \times 30 \times 15$ & 2.17 & $\mathrm{TL}$ & 165592 & 3337370 & 77.28 \\
\hline & \multirow{3}{*}{50} & $10 \times 10 \times 5$ & 2.18 & TL & 175886 & 3544370 & 3.17 \\
\hline & & $20 \times 20 \times 10$ & 2.02 & $\mathrm{U}$ & 184649 & 3694960 & 16.29 \\
\hline & & $30 \times 30 \times 15$ & 2.19 & $\mathrm{TL}$ & 181660 & 3659410 & 82.82 \\
\hline \multirow{21}{*}{80} & \multirow{3}{*}{10} & 10x10x5 & 2.08 & TL & 176192 & 3548750 & 3.66 \\
\hline & & $20 \times 20 \times 10$ & 2.02 & $\mathrm{U}$ & 177106 & 3543560 & 4.13 \\
\hline & & 30x30x15 & 2.12 & TL & 254072 & 5119760 & 15.42 \\
\hline & \multirow{3}{*}{20} & 10x10x5 & 2.08 & $\mathrm{TL}$ & 176192 & 3548750 & 4.08 \\
\hline & & $20 \times 20 \times 10$ & 2.01 & $\mathrm{U}$ & 186013 & 3721970 & 9.35 \\
\hline & & 30x30x15 & 2.08 & TL & 311142 & 6267280 & 33.69 \\
\hline & \multirow{3}{*}{30} & 10x10x5 & 2.04 & $\mathrm{TL}$ & 159910 & 3222500 & 5.97 \\
\hline & & $20 \times 20 \times 10$ & 2.00 & $\mathrm{U}$ & 203631 & 4076440 & 12.79 \\
\hline & & $30 \times 30 \times 15$ & 2.15 & $\mathrm{TL}$ & 165587 & 3338250 & 53.85 \\
\hline & \multirow{3}{*}{40} & 10x10x5 & 2.15 & TL & 208799 & 4210930 & 7.29 \\
\hline & & $20 \times 20 \times 10$ & 2.01 & $\mathrm{U}$ & 186013 & 3721970 & 38.97 \\
\hline & & $30 \times 30 \times 15$ & 2.17 & TL & 189712 & 3821980 & 109.40 \\
\hline & \multirow{3}{*}{50} & 10x10x5 & 2.16 & TL & 174219 & 3511110 & 8.23 \\
\hline & & $20 \times 20 \times 10$ & 2.02 & $\mathrm{U}$ & 184915 & 3700860 & 56.48 \\
\hline & & $30 \times 30 \times 15$ & 2.30 & $\mathrm{TL}$ & 152120 & 3061630 & 121.86 \\
\hline & \multirow{3}{*}{10} & 10x10x5 & 2.10 & $\mathrm{TL}$ & 153684 & 3095430 & 5.79 \\
\hline & & $20 \times 20 \times 10$ & 1.99 & $\mathrm{U}$ & 196119 & 3925370 & 8.81 \\
\hline & & 30x30x15 & 2.12 & $\mathrm{TL}$ & 223482 & 4502100 & 36.69 \\
\hline & \multirow{3}{*}{20} & $10 \times 10 \times 5$ & 2.10 & TL & 153684 & 3095430 & 6.40 \\
\hline & & $20 \times 20 \times 10$ & 2.01 & $\mathrm{U}$ & 186659 & 3734450 & 12.16 \\
\hline & & $30 \times 30 \times 15$ & 2.10 & TL & 295754 & 5958540 & 37.29 \\
\hline \multirow{9}{*}{90} & \multirow{3}{*}{30} & $10 \times 10 \times 5$ & 2.11 & TL & 289153 & 5824780 & 4.98 \\
\hline & & $20 \times 20 \times 10$ & 2.01 & $\mathrm{U}$ & 191289 & 3828780 & 17.33 \\
\hline & & $30 \times 30 \times 15$ & 2.12 & TL & 285497 & 5751080 & 96.53 \\
\hline & \multirow{3}{*}{40} & 10x10x5 & 2.11 & $\mathrm{TL}$ & 282344 & 5688670 & 4.26 \\
\hline & & $20 \times 20 \times 10$ & 2.01 & $\mathrm{U}$ & 186659 & 3734450 & 22.89 \\
\hline & & $30 \times 30 \times 15$ & 2.11 & TL & 300628 & 6054450 & 135.48 \\
\hline & & 10x10x5 & 2.06 & TL & 162432 & 3274480 & 8.07 \\
\hline & 50 & $20 \times 20 \times 10$ & 2.00 & $\mathrm{U}$ & 191379 & 3830250 & 34.11 \\
\hline & & $30 \times 30 \times 15$ & 2.13 & TL & 257475 & 5188020 & 169.76 \\
\hline & & 10x10x5 & 2.16 & TL & 200157 & 4035640 & 5.60 \\
\hline & 10 & $20 \times 20 \times 10$ & 2.03 & $\mathrm{U}$ & 166255 & 3325190 & 7.60 \\
\hline 100 & & $30 \times 30 \times 15$ & 2.10 & TL & 263559 & 5307420 & 24.92 \\
\hline & & $10 \times 10 \times 5$ & 2.16 & TL & 200157 & 4035640 & 6.52 \\
\hline & 20 & $20 \times 20 \times 10$ & 2.00 & $\mathrm{U}$ & 195031 & 3903910 & 16.01 \\
\hline & & 30x30x15 & 2.10 & TL & 258164 & 5198490 & 79.05 \\
\hline
\end{tabular}




\begin{tabular}{|c|c|c|c|c|c|c|c|}
\hline $\begin{array}{c}\text { Jumlah Kolom } \\
\text { Maks dalam } \\
\text { X or Y }\end{array}$ & $\begin{array}{c}\text { Jumlah radii } \\
\text { per poin }\end{array}$ & $\begin{array}{c}\text { Banyak } \\
\text { titik }\end{array}$ & FK & LOKası & $\begin{array}{l}\text { Volume } \\
\left(\mathrm{m}^{3}\right)\end{array}$ & $\begin{array}{c}\text { Berat } \\
(\mathrm{kN})\end{array}$ & $\begin{array}{l}\text { Waktu } \\
\text { (menit) }\end{array}$ \\
\hline & \multirow{3}{*}{30} & $10 \times 10 \times 5$ & 2.12 & TL & 174591 & 3518070 & 8.35 \\
\hline & & $20 \times 20 \times 10$ & 2.06 & $\mathrm{U}$ & 166498 & 3333480 & 22.41 \\
\hline & & $30 \times 30 \times 15$ & 2.14 & TL & 263276 & 5306780 & 75.41 \\
\hline & \multirow{3}{*}{40} & $10 \times 10 \times 5$ & 2.16 & TL & 127910 & 2571530 & 10.11 \\
\hline & & $20 \times 20 \times 10$ & 2.00 & $\mathrm{U}$ & 195031 & 3903910 & 30.45 \\
\hline & & $30 \times 30 \times 15$ & 2.12 & $\mathrm{TL}$ & 289302 & 5826370 & 144.15 \\
\hline & \multirow{3}{*}{50} & $10 \times 10 \times 5$ & 2.11 & TL & 297872 & 5998960 & 14.09 \\
\hline & & $20 \times 20 x 10$ & 1.99 & $\mathrm{U}$ & 202202 & 4047600 & 38.78 \\
\hline & & $30 \times 30 \times 15$ & 2.10 & $\mathrm{TL}$ & 289803 & 5839570 & 140.97 \\
\hline \multirow{15}{*}{110} & \multirow{3}{*}{10} & $10 \times 10 \times 5$ & 2.15 & TL & 150417 & 3031740 & 7.06 \\
\hline & & $20 \times 20 \times 10$ & 2.00 & $\mathrm{U}$ & 183751 & 3677030 & 15.52 \\
\hline & & $30 \times 30 \times 15$ & 2.04 & TL & 215724 & 4340750 & 30.74 \\
\hline & \multirow{3}{*}{20} & $10 \times 10 \times 5$ & 2.15 & TL & 150417 & 3031740 & 8.11 \\
\hline & & $20 \times 20 \times 10$ & 2.01 & $\mathrm{U}$ & 188258 & 3767370 & 19.85 \\
\hline & & $30 \times 30 \times 15$ & 2.10 & TL & 292587 & 5893780 & 61.07 \\
\hline & \multirow{2}{*}{30} & 10x10x5 & 2.08 & $\mathrm{TL}$ & 150558 & 3033660 & 11.89 \\
\hline & & $20 \times 20 \times 10$ & 2.02 & $\mathrm{U}$ & 192998 & 3861950 & 25.42 \\
\hline & & $30 \times 30 \times 15$ & 2.11 & TL & 292657 & 5894200 & 95.57 \\
\hline & \multirow{3}{*}{40} & 10x10x5 & 2.17 & TL & 200805 & 4048630 & 9.59 \\
\hline & & $20 \times 20 \times 10$ & 2.01 & $\mathrm{U}$ & 188258 & 3767370 & 35.37 \\
\hline & & $30 \times 30 \times 15$ & 2.10 & TL & 297208 & 5986560 & 126.44 \\
\hline & \multirow{3}{*}{50} & 10x10x5 & 2.14 & TL & 180211 & 3632680 & 11.62 \\
\hline & & $20 \times 20 \times 10$ & 1.92 & $\mathrm{U}$ & 190965 & 3821650 & 55.19 \\
\hline & & $30 \times 30 \times 15$ & 2.12 & TL & 232121 & 4674870 & 341.52 \\
\hline \multirow{15}{*}{120} & \multirow{3}{*}{10} & 10x10x5 & 2.12 & TL & 166704 & 3359600 & 9.72 \\
\hline & & $20 \times 20 \times 10$ & 2.00 & $\mathrm{U}$ & 197150 & 3945960 & 13.23 \\
\hline & & $30 \times 30 \times 15$ & 2.10 & TL & 303008 & 6103240 & 32.86 \\
\hline & \multirow{3}{*}{20} & 10x10x5 & 2.12 & $\mathrm{TL}$ & 166704 & 3359600 & 10.74 \\
\hline & & $20 \times 20 \times 10$ & 2.00 & $\mathrm{U}$ & 190349 & 3810640 & 21.24 \\
\hline & & $30 \times 30 \times 15$ & 2.11 & TL & 285894 & 5755880 & 66.41 \\
\hline & \multirow{3}{*}{30} & 10x10x5 & 2.12 & $\mathrm{TL}$ & 167435 & 3374580 & 12.27 \\
\hline & & $20 \times 20 \times 10$ & 2.08 & $\mathrm{U}$ & 149774 & 2996160 & 29.67 \\
\hline & & $30 \times 30 \times 15$ & 2.14 & TL & 163793 & 3300890 & 146.74 \\
\hline & \multirow{3}{*}{40} & $10 \times 10 \times 5$ & 2.19 & TL & 174653 & 3520120 & 7.01 \\
\hline & & $20 \times 20 \times 10$ & 2.00 & $\mathrm{U}$ & 190349 & 3810640 & 36.53 \\
\hline & & $30 \times 30 \times 15$ & 2.13 & TL & 166184 & 3349460 & 149.05 \\
\hline & \multirow{3}{*}{50} & 10x10x5 & 2.13 & $\mathrm{TL}$ & 155079 & 3126250 & 13.84 \\
\hline & & $20 \times 20 \times 10$ & 2.00 & $\mathrm{U}$ & 187247 & 3748180 & 54.80 \\
\hline & & $30 \times 30 \times 15$ & 2.12 & TL & 165772 & 3341170 & 194.69 \\
\hline \multirow{13}{*}{130} & \multirow{3}{*}{10} & 10x10x5 & 2.13 & TL & 173832 & 3504070 & 12.39 \\
\hline & & $20 \times 20 \times 10$ & 2.00 & $\mathrm{U}$ & 185623 & 3715740 & 33.57 \\
\hline & & $30 \times 30 \times 15$ & 2.11 & $\mathrm{TL}$ & 285594 & 5755000 & 127.90 \\
\hline & \multirow{3}{*}{20} & 10x10x5 & 2.10 & $\mathrm{TL}$ & 257680 & 5188300 & 8.63 \\
\hline & & $20 \times 20 \times 10$ & 2.00 & $\mathrm{U}$ & 192929 & 3861750 & 29.99 \\
\hline & & $30 \times 30 \times 15$ & 2.09 & $\mathrm{TL}$ & 264066 & 5319810 & 146.8 \\
\hline & \multirow{3}{*}{30} & $10 \times 10 \times 5$ & 2.13 & $\mathrm{TL}$ & 173832 & 3504070 & 20.49 \\
\hline & & $20 \times 20 \times 10$ & 2.07 & $\mathrm{U}$ & 151659 & 3036090 & 67.02 \\
\hline & & $30 \times 30 \times 15$ & 2.16 & TL & 220190 & 4437940 & 165.13 \\
\hline & & 10x10x5 & 2.12 & $\mathrm{TL}$ & 179832 & 3624830 & 15.88 \\
\hline & 40 & $20 \times 20 \times 10$ & 2.00 & $\mathrm{U}$ & 192929 & 3861750 & 50.20 \\
\hline & & $30 \times 30 \times 15$ & 2.13 & TL & 172624 & 3478060 & 176.29 \\
\hline & 50 & 10x10x5 & 2.14 & TL & 164806 & 3320930 & 16.54 \\
\hline
\end{tabular}




\begin{tabular}{|c|c|c|c|c|c|c|c|}
\hline $\begin{array}{l}\text { Jumian Koıоm } \\
\text { Maks dalam }\end{array}$ & $\begin{array}{c}\text { Jumlah radii } \\
\text { per poin }\end{array}$ & $\begin{array}{c}\text { Banyak } \\
\text { titik }\end{array}$ & rn & LOKASI & $\begin{array}{l}\text { Volume } \\
\left(\mathrm{m}^{3}\right)\end{array}$ & $\begin{array}{l}\text { Berat } \\
(\mathrm{kN})\end{array}$ & $\begin{array}{l}\text { Waktu } \\
\text { (menit) }\end{array}$ \\
\hline & & $20 \times 20 \times 10$ & 1.99 & $\mathrm{U}$ & 193556 & 3875140 & 58.49 \\
\hline & & $30 \times 30 \times 15$ & 2.10 & TL & 293677 & 5916620 & 212.42 \\
\hline \multirow{15}{*}{140} & \multirow{3}{*}{10} & 10x10x5 & 2.14 & TL & 171389 & 3455570 & 10.60 \\
\hline & & $20 \times 20 \times 10$ & 2.01 & $\mathrm{U}$ & 185606 & 3713960 & 14.79 \\
\hline & & $30 \times 30 \times 15$ & 2.13 & $\mathrm{TL}$ & 151957 & 3063860 & 61.68 \\
\hline & \multirow{3}{*}{20} & 10x10x5 & 2.14 & TL & 171389 & 3455570 & 12.11 \\
\hline & & $20 \times 20 \times 10$ & 2.00 & $\mathrm{U}$ & 190860 & 3819400 & 30.22 \\
\hline & & $30 \times 30 \times 15$ & 2.09 & $\mathrm{TL}$ & 318533 & 6416010 & 93.52 \\
\hline & \multirow{4}{*}{30} & 10x10x5 & 2.14 & $\mathrm{TL}$ & 164812 & 3321990 & 13.26 \\
\hline & & $20 \times 20 \times 10$ & 2.00 & $\mathrm{U}$ & 197689 & 3957250 & 76.09 \\
\hline & & $30 \times 30 \times 15$ & 2.17 & $\mathrm{TL}$ & 209503 & 4222890 & 138.03 \\
\hline & & $10 \times 10 \times 5$ & 2.14 & TL & 171389 & 3455570 & 14.44 \\
\hline & \multirow[t]{2}{*}{40} & $20 \times 20 \times 10$ & 2.00 & $\mathrm{U}$ & 190860 & 3819400 & 54.44 \\
\hline & & 30x30x15 & 2.10 & TL & 300824 & 6060500 & 194.42 \\
\hline & \multirow[t]{3}{*}{50} & 10x10x5 & 2.15 & TL & 175502 & 3537030 & 20.28 \\
\hline & & $20 \times 20 \times 10$ & 2.02 & $\mathrm{U}$ & 181917 & 3639500 & 74.49 \\
\hline & & $30 \times 30 \times 15$ & 2.12 & TL & 276689 & 5575590 & 266.84 \\
\hline \multirow{15}{*}{150} & \multirow{4}{*}{10} & 10x10x5 & 2.11 & TL & 297031 & 5983460 & 11.67 \\
\hline & & $20 \times 20 \times 10$ & 2.01 & $\mathrm{U}$ & 191699 & 3836970 & 23.55 \\
\hline & & 30x30x15 & 2.17 & TL & 239949 & 4831670 & 57.05 \\
\hline & & 10x10x5 & 2.15 & TL & 169640 & 3420680 & 12.34 \\
\hline & \multirow[t]{2}{*}{20} & $20 \times 20 \times 10$ & 2.00 & $\mathrm{U}$ & 187908 & 3760810 & 33.49 \\
\hline & & $30 \times 30 \times 15$ & 2.15 & $\mathrm{TL}$ & 211478 & 4264250 & 119.32 \\
\hline & \multirow{4}{*}{30} & 10x10x5 & 2.16 & TL & 171123 & 3448690 & 12.50 \\
\hline & & $20 \times 20 \times 10$ & 2.06 & $\mathrm{U}$ & 174780 & 3498920 & 48.12 \\
\hline & & 30x30x15 & 2.11 & TL & 305170 & 6148400 & 184.74 \\
\hline & & $10 \times 10 \times 5$ & 2.15 & TL & 169640 & 3420680 & 46.14 \\
\hline & \multirow[t]{3}{*}{40} & $20 \times 20 \times 10$ & 2.00 & $\mathrm{U}$ & 187908 & 3760810 & 83.51 \\
\hline & & $30 \times 30 \times 15$ & 2.16 & TL & 172915 & 3484720 & 298.10 \\
\hline & & 10x10x5 & 2.09 & $\mathrm{TL}$ & 293250 & 5909150 & 24.87 \\
\hline & \multirow[t]{2}{*}{50} & $20 \times 20 \times 10$ & 2.01 & $\mathrm{U}$ & 195814 & 3920260 & 105.20 \\
\hline & & $30 \times 30 \times 15$ & 2.17 & TL & 206034 & 4154070 & 322.33 \\
\hline
\end{tabular}

Keterangan : $\mathrm{B}=$ barat; $\mathrm{BL}=$ barat laut $\mathrm{U}=$ utara; $\mathrm{TL}=$ timur laut $\mathrm{T}=$ timur

\section{KESIMPULAN}

Dengan menganalisis kestabilan lereng secara 3D estimasi volume potensi longsoran dapat diketahui sehingga resiko dapat terukur. Untuk menentukan estimasi volume, FK suatu massa longsoran perlu dihitung terlebih dahulu. Untuk mendapatkan FK, bidang longsor dibuat sehingga berbentuk seperti massa longsoran dan didiskritisasi dalam kolom vertikal, kemudian dari kolom-kolom tersebut baru dapat dilakukan perhitungan FK. Penentuan estimasi volume potensi longsoran dengan metode pencarian bidang longsor Grid Search perlu dilakukan dengan berbagai variasi variabel seperti jumlah kolom maks di sumbu $\mathrm{x}$ atau $\mathrm{y}$, jumlah radii per poin, dan banyak titik dalam grid box karena besar volume sangat bergantung pada variabel-variabel tersebut. Estimasi volume potensi longsoran yang didapat sebesar $190.000 \mathrm{~m}^{3}$ dengan lokasi potensi longsoran di utara pit. Berdasarkan hasil analisis, analisis 3D LEM di masa depan dianjurkan untuk 
memakai teknik optimasi dalam pencarian bidang longsor agar dapat lebih efisien dalam hal waktu komputasi.

\section{UCAPAN TERIMA KASIH}

Penulis mengucapkan terima kasih kepada pihak-pihak yang telah mendukung hingga penelitian ini dapat dirampungkan.

\section{PUSTAKA}

1. Albataineh, N. 2006. Slope Stability Analysis Using 2D and 3D Methods. Thesis. University of Akron.

2. Amala, S.A. 2018. Analisis Kestabilan Lereng Tunggal 3D Berdasarkan Hasil Kekuatan Batuan Utuh dan Massa Batuan Batugamping PT OMYA Indonesia Tahunan, Rembang, Jawa Tengah. Skripsi. Universitas Trisakti.

3. Bishop, A.W. 1955. The Use the Slip Circle in the Stability Analysis of Slopes, Geotechnique, Vol 5, No. 1, pg 7-17.

4. Cheng, Y.M. and Yip, C.J. 2007. Three-Dimensional Asymmetrical Slope Stability Analysis Extension of Bishop's, Janbu's, and Morgenstern-Price's Techniques, ASCE Journal of Geotechnical and Geoenvironmental Engineering, 133(12), 1544-1555. https://doi.org/10.1061/(ASCE)10900241(2007)133:12(1544)

5. H.A. Ardhi, Masagus Ahmad Azizi, Irfan Marwana, Pancanita N. Hartami, Bani Nugroho. 2017. Perbandingan Analisis Stabilitas Lereng Metode Kesetimbangan Batas Dengan Metode Elemen Hingga Menggunakan Pendekatan Probabilistik, Seminar Nasional Geomekanika 4 (SNG4) Padang, 179-185

6. Hartanti, N.A. 2018. Analisis Kestabilan Lereng Batugamping di PT OMYA Indonesia, Rembang, Jawa Tengah Menggunakan Metode Kesetimbangan Batas Pada Software Slide3. Skripsi. Universitas Trisakti.

7. M.A. Azizi dan Rr Harminuke Handayani. 2011. Karakterisasi Parameter Masukan Untuk Analisis Kestabilan Lereng Tunggal (Studi Kasus Di PT. Tambang Batubara Bukit Asam Tbk. Tanjung Enim, Sumatera Selatan), AVOER 2011, Fakultas Teknik Universitas Sriwijaya

8. M.A. Azizi, S. Kramadibrata, R.K. Wattimena, I.D. Sidi. 2013. Characterization of the distribution of physical and mechanical properties of rocks at the Tutupan coal mine, South Kalimantan, Indonesia, EUROCK 2013 - Rock Mechanics for Resources, Energy \& Enviroment, 213-216.

9. M.A. Azizi, S. Kramadibrata, R.K. Wattimena, I.D. Sidi. 2013. Probabilistic Analysis of Physical Models Slope Failure, Procedia Earth and Planetary Science 6, 411-418.

10.M.A. Azizi, S. Kramadibrata, R.K. Wattimena, I.D. Sidi. 2014. Risk Assessment Of Open Pit Slope Design At PT Adaro Indonesia, Indonesian Mining Journal 17 (3), 113-121.

11.Prakoso, G. 2018. Analisis Kestabilan Lereng Dengan Metode Kesetimbangan Batas Berdasarkan Hasil Pemetaan Geoteknik Sampel Batuan Inti Batugamping di PT OMYA Indonesia, Sale, Rembang, Jawa Tengah. Skripsi. Universitas Trisakti.

12.R.A. Abdullah, Dedy Yusufianshah, Mohd Asmawisham Alel, Siti Nurafida Jusoh, Mohd Azril Hezmi, Nor Zurairahetty Mohd Yunusand, Ahmad Nazri Ali, 
Masagus Ahmad Azizi. 2018. Slope Stability Analysis Of Quarry Face at Karang Sambung District, Central Java, Indonesia, International Journal Of Civil Engineering \& Technology (IJCIET) 9 (1), 857-864.

13.R.K. Wattimena, S. Kramadibrata, I.D. Sidi, I. Arif, M.A. Azizi. 2012. Probabilistic Analysis of Single Bench Using New Slope Stability Curves, ISRM Regional Symposium-7th Asian Rock Mechanics Symposium

14. R.K. Wattimena, S. Kramadibrata, I.D. Sidi, M.A. Azizi. 2013. Developing coal pillar stability chart using logistic regression, International Journal of Rock Mechanics and Mining Sciences 58, 55-60

15. Rocscience. 2018. Slide 2018: Grid Search. www.rocscience.com. (diakses 1 Agustus 2018)

16. Rocscience. 2018. Slide3 - 3D Limit Equilibrium Slope Stability Overview. www.rocscience.com (diakses 28 Maret 2018)

17. S. Kramadibrata, R.K. Wattimena, I.D. Sidi, M.A. Azizi, Y. Adriansyah. 2012. Open Pit Mine Slope Stability and Uncertainty, ISRM Regional Symposium7th Asian Rock Mechanics Symposium.

18. S. Kramadibrata, R.K. Wattimena, M.A. Azizi, Y. Wicaksana, I.D. Sidi. 2013. Physical modeling and simulation of slope failure by means of centrifuge acceleration, ISRM International Symposium-EUROCK 2013. 
